Diego Quevedo Costa diegoqcosta@gmail.com Graduado em Administração pela Universidade de Caxias do Sul. Caxias do Sul - RS - BR.

Daniel Hank Miri

dhmiri@ucs.br

Bolsista PROSUC/CAPES

no curso de Mestrado em Administração pelo Programa de Pós-Graduação em Administração da Universidade de Caxias do Sul. Caxias do Sul - $R S$ - BR

\section{Cassiane Chais} cassichais@gmail.com Doutoranda em Administração na Universidade de Caxias do Sul com Bolsa PROSUC/ CAPES. Caxias do Sul - RS $B R$.

\section{Juliana Matte ju.cxs1@gmail.com Doutoranda em Administração no Programa de Pós-Graduação em Administração - PPGA da Universidade de Caxias do Sul - UCS com bolsa FAPERGS/ CAPES. Caxias do Sul - RS - $B R$}

Paula Patrícia Ganzer ganzer.paula@gmail.com Pós-Doutoranda em Administração no Programa de Pós-Graduação em Administração na Universidade de Caxias do Sul. Caxias do Sul - $R S$ - BR

Pelayo Munhoz Ole pelayo.olea@gmail.com Doutor em Administração e Direção de Empresas. Professor da Universidade de Caxias do Sul. Caxias do Sul - RS - BR.
ARTIGOS

\section{EFICIÊNCIA NO ABASTECIMENTO DE MATERIAIS EM UMA LINHA DE MONTAGEM MULTIPRODUTO}

\author{
EFFICIENCY IN SUPPLYING MATERIALS IN A \\ MULTIPRODUCT ASSEMBLY LINE
}

\section{RESUMO}

Apesar de alguns avanços, a logística continua sendo uma área relativamente inexplorada no que concerne ao aumento de produtividade. Diante disso, o tema deste trabalho consiste na logística interna de materiais e no abastecimento da linha multiproduto de uma fábrica de tratores localizada em Caxias do Sul, Rio Grande do Sul. Objetivou-se, assim, identificar oportunidades de melhoria nos processos, a fim de aumentar a eficiência na logística interna do abastecimento de materiais na linha de montagem. Para alcançar o objetivo proposto, procedeu-se a uma pesquisa qualitativa e exploratória, por meio de um estudo de caso único, fundamentado em entrevistas individuais em profundidade com dez profissionais diretamente ligados ao tema em questão. Após a análise de conteúdo das entrevistas, identificaram-se oportunidades de melhorias nos processos de logística de abastecimento, como a falta de confiabilidade nos sistemas utilizados, a necessidade de treinamentos e as informações disponibilizadas.

Palavras-chave: Logística interna. Linha multiproduto. Abastecimento de materiais.

\begin{abstract}
Despite some advances, logistics remains a relatively unexplored area of increased productivity. Therefore, the theme of this work is the internal logistics of materials and the supply of the multiproduct line of a tractor factory located in Caxias do Sul, Rio Grande do Sul. The objective was to identify opportunities for improvement in the processes, in order to to increase the efficiency in the internal logistics of the supply of materials on the assembly line. To reach the proposed objective, a qualitative and exploratory research was carried out, through a single case study, based on individual in-depth interviews with ten professionals directly related to the subject in question. After analyzing the content of the inter-
\end{abstract}


views, opportunities were identified for improvements in supply logistics processes, such as the lack of reliability in the systems used, the need for training and the information available.

Keywords: Internal Logistics. Multiproduct line. Supply of materials.

\section{INTRODUÇÃO}

Devido ao aumento da concorrência, um desafio presente nas indústrias brasileiras é buscar diferenciação competitiva em fatores, como preço e qualidade, o que tem levado as empresas a reavaliarem atitudes e processos e a criarem novos paradigmas voltados à obtenção de melhorias e vantagens competitivas (BARCELOS JÚNIOR, 2002). Com o processo de globalização e uma oferta maior que a deman$\mathrm{da}$, as empresas precisaram adaptar-se a uma realidade de competição em escala global, o que implicou uma revisão significativa de suas prioridades competitivas, especialmente em termos de custo e qualidade (PIRES, 2009).

Nesse cenário, a cadeia de suprimentos e o gerenciamento de operações amadureceram a partir de mudanças na forma de abordar as questões operacionais e econômicas, que passou a levar em conta o ambiente mais amplo e os aspectos sociais que integram as organizações contemporâneas. A integração bem-sucedida de fatores econômicos e ambientais e as metas de sustentabilidade social têm sido, assim, o objetivo das principais cadeias de suprimentos e operações (FENG; ZHU; LAI, 2017).

A cidade de Caxias do Sul abriga 20 das 500 maiores empresas da região Sul do Brasil, assim como diversas indústrias entre as maiores no seu campo de atuação no país. A indústria constitui o maior segmento econômico da cidade: com 2.332 empresas metalúrgicas e mecânicas instaladas, gera 17.658 empregos diretos e representa $53,40 \%$ dos segmentos econômicos municipais (SIMECS, 2017).

Situada nessa cidade, está a fábrica de tratores da empresa Agrale S.A., local em que foi aplicada esta pesquisa. Como essa fábrica visava aumentar a eficiência operacional do processo de logística de abastecimento de materiais de uma linha de montagem de tratores multiproduto, efetuou-se uma pesquisa qualitativa com dez profissionais da área produtiva.

O objetivo deste estudo consistiu, portanto, em identificar oportunidades de melhoria nos processos, com o propósito de aumentar a eficiência na logística interna do abastecimento de materiais nessa linha de montagem. A seguir, apresenta-se o referencial teórico que embasa esta pesquisa, subdividido em cadeia de suprimentos, logística e sistemas de controle de produção, assim como a metodologia empregada para o alcance do objetivo proposto, os resultados da pesquisa e as considerações finais.

\section{REFERENCIAL TEÓRICO}

\subsection{CADEIA DE SUPRIMENTOS}

A cadeia de suprimentos constitui um tema central dentro das empresas há pelo menos 80 anos, tendo proporcionado diversas inovações gerenciais ao longo do tempo. Como exemplo dessas inovações, podem-se citar Henry Ford na Primeira Guerra Mundial, Alfred Sloan na década de 1930, Toyota nas décadas de 40 a 70 e o Consórcio da Volkswagen em Resende na década de 90 (FIGUEIREDO; FLEURY; WANKE, 2013).

A cadeia de suprimento consiste em uma abordagem que engloba todos os processos, tanto diretos, quanto indiretos, para atender ao pedido de um cliente. Nesses processos, estão incluídos fabricantes, fornecedores, transportadoras, armazéns, varejistas e até mesmo o consumidor final, envolvendo áreas como marketing, desenvolvimento de produto, produção, distribuição e atendimento ao cliente (CHOPRA; MEINDL, 2016).

Para Paoleschi (2014), a gestão da cadeia de suprimentos requer a integração dos processos internos, que engloba o departamento de produtos, e externos, que abarca o departamento de compra/suprimentos e as relações com os fornecedores. A gerência tem, dessa maneira, a res- 
ponsabilidade de controlar fortemente as principais cadeias de suprimentos para melhorar os processos de manufatura, a logística e o planejamento da produção (YAZDANI et al., 2017).

\subsection{LOGÍSTICA}

A área da logística busca, sobretudo, cumprir os requisitos dos clientes, ofertando os bens ou serviços no local e no tempo correto. Como parte dos negócios vinculados à empresa, a logística é constituída de cinco atividades primordiais: gerenciamento de estoque, transporte, armazenagem ou estocagem, tecnologia da informação e gerenciamento da produção ou operação (GRANT, 2013).

Para Nogueira (2012), um dos tópicos mais importantes da cadeia logística é a armazenagem, que apresenta, como principal função, a administração do espaço e do tempo. Um sistema de armazenagem, quando bem aplicado, pode evitar e solucionar diversos problemas que influenciam diretamente o processo produtivo e a distribuição dos produtos, otimizando espaços e recursos, diminuindo o custo final do produto e aumentando a competitividade.

O processo operacional logístico de peças, conforme Boysen et al. (2015), é dividido em logística externa, logística interna e logística reversa. A logística externa implica todas as atividades necessárias para fornecer as peças advindas do fornecedor (externo ou interno). Já a logística interna assume todos os passos inerentes à produção, desde o recebimento até a distribuição e a organização na borda da linha. E a logística reversa, por sua vez, requerida no final do processo, engloba aspectos como devolução e retorno de peças defeituosas e embalagens vazias. A movimentação de materiais é uma atividade que demanda esforço, sendo necessários equipamentos adequados para cada tipo de material (CAXITO, 2014; YAZDANI et al., 2017).

\subsection{SISTEMAS DE CONTROLE DE PRODUÇÃO}

Moreira (2012) divide, genericamente, os sistemas de controle de produção em dois tipos: produção empurrada e produção puxada. A produção empurrada procura prever as necessidades do cliente, baseando-se em uma previsão de demanda; caso essa demanda não ocorra ou demore a se confirmar, gerará o acúmulo de estoque. Já a produção puxada, base da filosofia Just in Time (JIT), entende que a previsão de demanda puxa a produção, partindo da lógica de que a produção começa no término da linha de produção, ou seja, no cliente; assim, só começa a produzir a partir da necessidade do cliente, não ocasionando estoques em excesso.

Já Wang, H., Gong e Wang, S. (2017) fazem uma comparação entre os principais sistemas de controle de produção. Enquanto o JIT é adequado para um pequeno lote com produção de grande variedade, o MRP (Manufacturing Resources Planning) é apropriado para um lote grande com produção de pequena variedade. Além disso, os autores ressaltam que uma estrutura organizacional otimizada de processamento de informações é capaz de reduzir o atraso na tomada de decisões.

\section{METODOLOGIA}

Para esta pesquisa, usou-se a abordagem qualitativa de natureza exploratória (LAKATOS; MARCONI, 2011), com aplicação de entrevistas estruturadas (DIEHL; TATIM, 2004). O roteiro das entrevistas foi elaborado a partir de uma adaptação dos estudos de Teixeira (2008) e Rodrigues (2016), sendo aplicado o mesmo roteiro a todos os participantes da pesquisa.

Constituindo um estudo de caso único (GIL, 2010) na montadora de tratores Agrale S.A., foram realizadas entrevistas com dez profissionais relevantes do processo produtivo dessa empresa durante o mês de março de 2017. As entrevistas geraram um total de três horas de gravação de áudio e 50 páginas de transcrição. Para apurar os resultados, procedeu-se à análise de conteúdo, conforme proposta por Bardin (2004); dessas entrevistas, que foram divididas em categorias e subcategorias com o auxílio do software NVivo $11{ }^{\circledR}$. 


\subsection{OBJETO DE PESQUISA}

A Agrale iniciou suas atividades em 14 de dezembro de 1962. Atualmente, é composta por cinco unidades, das quais três situam-se na cidade de Caxias do Sul, Rio Grande do Sul, uma fica localizada em São Mateus, Espírito Santo, e outra está em Mercedes, Argentina. Cada unidade tem suas peculiaridades no que diz respeito aos processos produtivos, possuindo processos de fabricação e montagem de diferentes produtos (AGRALE, 2014).

O foco deste estudo foi a unidade I (matriz), que fica localizada na BR 116, km 145, n. ${ }^{\circ}$ 15.104, bairro São Ciro, CEP 95059-520, no município de Caxias do Sul. Nessa unidade da Agrale, concentram-se a linha de montagem de tratores e motores estacionários, o centro administrativo, o centro de fabricação de peças e componentes para manufatura, um centro de distribuição de peças de reposição e um centro de desenvolvimento de novos produtos (AGRALE, 2014).

Essa unidade conta com 662 funcionários. Ao todo, a Agrale possui 1.083 funcionários distribuídos em suas cinco unidades (AGRALE, 2014).

\section{APRESENTAÇÃO E ANÁLISE DOS RESULTADOS}

A primeira questão das entrevistas buscou identificar as funções e as atividades desempenhadas por cada um dos participantes na empresa-foco deste estudo. A seguir, no quadro 1, apresentam-se a descrição das funções e as respectivas atividades dos entrevistados.

Quadro 1 - Funções e atividades dos funcionários entrevistados

\section{Função}

Coordenador de logística

Técnico de logística

Técnico de planejamento e controle da produção (PCP)

Técnico da linha de montagem

Almoxarife especializado

Almoxarife 1

Almoxarife 2

Almoxarife 3

\section{Atividade desempenhada}

"Fazer a gestão das equipes, melhorar e desenvolver novos processos que visam à otimização do fluxo logístico, o abastecimento de linha e à acurácia de estoques".

"Como gestor de almoxarifado, técnico de almoxarifado, minha função hoje é gerenciar o sistema de WMS [Warehouse Management System], a parte de efetividades, inventários tanto cíclicos como os pontuais e a parte de leilão e vendas de materiais obsoletos".

"Atualmente exerço a função de técnico em PCP, responsável pela programação dos setores de usinagem e estamparia na unidade 1".

"Responsável técnico das linhas de montagem de motores e tratores, processos de montagem, PCP e o administrativo da linha".

“[...] sou responsável pela logística interna, para disponibilizar as peças que os montadores precisam, na quantidade correta e nos estágios corretos, sempre procurando manter a acurácia dos estoques; também cuido da lista de faltas de peças".

"O foco maior nosso como almoxarife é abastecimento de linha, manter os estoques alinhados tanto na linha de montagem quanto no almoxarifado".

"[...] trabalho como almoxarife, minha função desempenhada é na parte do recebimento, toda entrada de materiais, conferência do material, quantidades, volumes, notas fiscais; enfim, tudo que envolve a quantidade de materiais dentro da empresa".

“[...] trabalho com separação de peças, atendimento do DPER, que é um setor que trabalha com peças de reposição que é para mercado externo e interno".

Almoxarife 4

"Separação e envio de peças entre fábricas".

Inventarista

"Responsável pelos inventários realizados na empresa".

Fonte: elaborado pelos autores (2018). 
Já a segunda questão das entrevistas procurou identificar o entendimento dos entrevistados sobre os objetivos da logística. As respostas dos participantes demonstraram que não são todos que conhecem, com clareza, os objetivos da empresa.

Em relação às metas da logística, o coordenador de logística afirmou que se trata do "[...] atendimento das entregas do produto certo nas quantidades certas, atrelado ao Just in Time. Toda a logística tem por objetivo ter o menor estoque necessário, atender, com a maior assertividade possível, à demanda do cliente interno e prezando pela qualidade do produto e a acurácia do estoque.”

A terceira questão das entrevistas, por sua vez, visou averiguar a existência de programas nos processos logísticos que possibilitem avaliar todo o processo de produção, desde o recebimento até o abastecimento da linha de montagem. O processo operacional logístico de peças, para Boysen et al. (2015), pode ser dividido em logística externa, interna e reversa. No caso da empresa analisada, nem todas as peças passam por um processo idêntico, uma vez que este varia conforme o fornecedor e o modo como é entregue no ponto de consumo interno.

O almoxarife 2 destacou dois sistemas responsáveis pelos processos logísticos: “[...] o ABT, e o WMS, esses sistemas são suficientes para identificar todas as entradas, hora, data, descrição do produto até o processamento e saída, mas não é totalmente usada." Já o técnico de PCP demonstrou outra visão: "[...] tanto o ABT, quanto o WMS controlam o nosso processo e nos pontuam como ele funciona, se está funcionando bem ou se existem algumas falhas, a única forma que eu vejo para controlar isso é por meio desses dois sistemas."

O almoxarife especializado citou o WMS, programa específico da logística, como responsável por analisar o processo: “[...] WMS, sistema que acompanha desde o recebimento, quando vem para o almoxarifado, os locais de alocação, os pickings múltiplos na linha e pulmões no almoxarifado [...]." O técnico dos almoxarifados também enfatizou o mesmo programa: “[...]
WMS, que consegue visualizar toda a parte do processo e trabalhar em cima para ir ajustando e vendo o que é possível melhorar no processo, tornando mais rápido e assertivo."

No roteiro de entrevistas, a quarta questão destinou-se a averiguar se o entrevistado tinha alguma sugestão de melhoria nos processos da logística. Para o técnico de PCP, essa era uma falha e uma oportunidade de melhoria no processo, uma vez que o sistema utilizado pela logística permite esse tipo de situação. Para o técnico da linha de montagem, o trabalho para melhorar o processo poderia ser realizado com base nos indicadores de abastecimento da linha de montagem. Segundo ele, “[...] devem ser mais bem trabalhados esses indicadores, pois dá para avaliar os pontos de abastecimento que precisam melhorar [...]."

Aspectos como logística e armazenagem, conforme ressaltam Dubey et al. (2017), também devem ser aprimorados, tendo em vista que mudanças particulares nessas operações permitirão que organizações e cadeias de suprimentos tornem-se melhores ambientalmente, auxiliando na viabilidade e na estabilidade econômica. Tendo isso em vista, a quinta questão das entrevistas versou sobre a identificação dos pontos críticos e gargalos da logística. Essa análise dos pontos críticos e gargalos é uma categoria a posteriori da pesquisa que surgiu durante a análise das entrevistas.

Para o técnico de PCP da empresa, o ponto crítico consiste na dificuldade do gerenciamento dos estoques: "[...] percebo que nós temos muita dificuldade no gerenciamento dos estoques, por diversos motivos, não só por responsabilidade da logística, mas por responsabilidade por estrutura de produto, falhas de movimentação, setores que permanecem abertos [...]." O tema abordado pelo técnico de PCP da empresa vai ao encontro do que declara Castiglioni (2013) acerca do gerenciamento de estoque, uma vez que o gerenciamento de materiais constitui um dos pontos mais vitais da logística, exigindo técnicas específicas para alcançar a eficiência da racionalização e da economia desejada. 
Nesse sentido, é possível afirmar que os pontos críticos dos sistemas utilizados pela empresa afetam diretamente o desempenho da logística. Para Nogueira (2012), um sistema de armazenagem, quando bem aplicado, pode evitar e solucionar diversos problemas que influenciam, diretamente, o processo produtivo e a distribuição dos produtos, otimizando espaços e recursos, diminuindo o custo final do produto e aumentando, assim, a competitividade.

A sexta questão feita aos entrevistados abordou os pontos críticos e os gargalos entre logística e produção na visão de cada entrevistado. Já os pontos críticos e gargalos entre logística e linha de montagem foram abordados na sétima questão do instrumento de pesquisa.

Para o coordenador de logística, o gargalo entre essas duas áreas estava na "[...] gestão da informação da produção com a logística, que tem por prioridade em movimentar e abastecer a linha [...]." Para o almoxarife 1, "é a falta de comunicação, a logística e produção deveriam trabalhar ambas com o mesmo objetivo e com uma comunicação clara." Outro aspecto citado como ponto crítico pelos entrevistados foi "as embalagens que eles distribuem as peças pro nosso setor, porque geralmente gera retrabalho pra gente colocar de uma forma apropriada, para alocar no nosso estoque", como afirmou o almoxarife 3. Já o almoxarife 4 disse que a falta de um mesmo conhecimento de todo o processo criava um gargalo. Segundo ele, os "funcionários não têm o mesmo conhecimento em torno do processo."

A oitava questão do roteiro de entrevista abordou a existência de ferramentas para auxiliar na produção puxada dentro da empresa. Os entrevistados mencionaram o que já existe na empresa e as oportunidades de implementação de ferramentas para puxar a produção.

Para Moreira (2012), na produção puxada, base de filosofia JIT, a previsão de demanda puxa a produção. A lógica desse modelo é que a produção inicia com a necessidade do cliente, de maneira que não são produzidos estoques em excesso.

Para o técnico de PCP, o Kanban den- tro do sistema produtivo acabaria gerando estoques, contrariando a premissa da empresa de reduzir os estoques ao máximo:

[...] trabalhamos bastante forte a redução de estoques ao máximo possível e a ordem de produção dentro do sistema. Agrale trabalha no Just in Time. Conforme as necessidades da linha, nós temos um período para produzir e entregar isso; o fato de nos agregar um sistema de Kanban dentro do nosso processo, vamos estar falando de estoque, vamos ter que alimentar um sistema intermediário e criar pontos de estoques, gerando custos para empresa (ENTREVISTADO - TÉCNICO PCP).

Kanbans são cartões de autorização de produção que sinalizam às estações o montante e o tempo adequado para reabastecer o estoque de estações a jusante. Os Kanbans viajam com um lote de produtos/componentes, continuando sua jornada por meio de vários estágios de fabricação (PIPLANI; ANG, 2018).

\section{1 ANÁLISE DE GERENCIAMENTO DE ESTOQUES}

\subsubsection{Gerenciamento de inventários para os entrevistados}

O gerenciamento de inventários foi abordado na nona questão do roteiro de entrevista, que interrogou sobre as metas para redução de estoques e giro de matérias e a existência de programas de gerenciamento. O técnico de logística responsável pelos inventários da empresa relatou a metodologia existente para atender os inventários: "[...] sim, existe. Hoje, trabalhamos com inventários cíclicos, em que são trabalhados a curva $\mathrm{ABC}$, e depois há os pontuais, e ainda existem os inventários anuais realizados no final de cada ano."

Já o inventarista enfatizou o trabalho realizado, dissertando acerca da forma de realização dos inventários e da nova metodologia aplicada na empresa: 
[...] quando eu entrei, nós não tínhamos nenhuma planilha, recebíamos os códigos em um papel de pão [...]. A partir daí, começou a fazer uma planilha de erros de inventários e todos os problemas que temos, e, com o passar do tempo, começamos a programar o inventario cíclico; este inventário cíclico ajuda muito, seria nossa melhor ação [...] (ENTREVISTADO - INVENTARISTA).

Para o almoxarife especializado, são feitos os inventários cíclicos e os inventários pontuais; esses são realizados quando se percebe a falta de um item na montagem. O almoxarife 1 citou "o inventário geral, feito uma vez ao ano". E o técnico de logística comentou sobre o trabalho realizado dentro da empresa para a redução de estoques: "nós temos metas para reduzir os estoques, sim, estamos trabalhando muito em cima disto aí [...]. Estamos trabalhando em cima de itens que não têm movimentação [...]."

A esse respeito, cabe mencionar o efeito chicote, por exemplo, que se refere a um fenômeno no qual baixas variações na demanda causam mudanças significativas na produção para fornecedores, com custos associados. Enquanto a previsão tem um impacto direto na geração de pedidos, a visibilidade do prazo de entrega é essencial para projetar uma produção/distribuição de alta qualidade (LIN et al., 2017).

\subsubsection{Auditorias na área de logística para os entrevistados}

O processo da logística interna começa no recebimento e vai até o abastecimento na borda da linha. Tendo isso em vista, a décima questão do roteiro de entrevista buscou averiguar a existência de procedimentos de auditorias e os desdobramentos das auditorias dentro da logística.

O coordenador de logística explicou que não existem auditorias em todos os processos, salientando que, "nos almoxarifados, são realizadas as auditorias de endereçamento e eventualmente algumas contagens que são feitas pelos inventários cíclicos pois não deixam de ser uma auditoria de materiais [...]. No transporte interno e na expedição não são feitas auditorias." O coordenador mencionou, ainda, as ações corretivas dentro da logística: "procura-se estabelecer alguns planos de contenções ou planos de ações, então depende de cada caso, mas, sim, existe uma ação corretiva."

Para o técnico de logística, o sistema WMS usado pela logística realizava auditorias no recebimento de materiais, "[...] com uma contagem cega, chega o material, dá entrada na nota fiscal, $[. .$.$] e o WMS manda contar, ge-$ rando tarefa de contagem cega. O operador não [...] vai apontar se deu certo; com a nota ok, segue à frente, se não der, gera uma divergência."

\subsubsection{Não conformidades nos processos logísticos pelos entrevistados}

No roteiro de entrevista, a décima primeira questão tratou das ações relativas às não conformidades dentro do processo logístico. A esse respeito, enquanto o técnico da linha de montagem afirmou que desconhece ações para evitar reincidências de não conformidades na logística, o almoxarife especializado disse que "não existe nada implementado para evitar reincidências de não conformidades; sempre quando acontece algo nesse aspecto, é feita a correção pontual do problema." O almoxarife 3 também falou que não existe nada nesse sentido e complementou: "[...] geralmente acontece reincidências de não conformidade em algumas peças [...]". E o almoxarife 1 reiterou que, "na verdade, não existe um processo específico para evitar reincidências no processo logístico."

Verificou-se, assim, uma divergência entre os entrevistados sobre auditorias e procedimentos para evitar não conformidades. Ao passo que o coordenador e o técnico de logística confirmaram a existência de procedimentos implementados, os demais entrevistados que trabalhavam na logística desconheciam ações para combater as não conformidades no processo logístico, evidenciando uma falha na comunicação dentro da área da logística. 


\subsection{ANÁLISE DE EMBALAGENS}

A décima segunda pergunta do roteiro de entrevista questionava se os entrevistados tinham conhecimento da existência de um manual de embalagem da empresa. O almoxarife especializado, o técnico da linha de montagem e o técnico de PCP afirmaram desconhecer a existência de um manual de embalagem dentro da empresa. Percebe-se, assim, que pessoas envolvidas diretamente com a fabricação, a movimentação e o uso final das peças desconheciam esse manual. Alguns entrevistados sabiam de sua existência, mas desconheciam seu conteúdo, evidenciando, dessa forma, uma falha na troca de informações dentro da empresa, o que dificulta o trabalho e o bom desempenho organizacional.

A décima terceira questão também tratou de embalagens, perguntando aos entrevistados se existia uma metodologia ou um procedimento com o intuito de eliminar as não conformidades, bem como se tinham alguma sugestão de melhoria nesse quesito.

Para o técnico de PCP, falta retorno da linha de montagem e da logística sobre quais são as embalagens corretas que devem ser usadas para cada item:

[...] as necessidades devem partir direto das linhas, [...] cliente final é a linha de montagem. Ele tem um processo de armazenamento na linha, $[\ldots]$ as linhas de montagem, nos últimos anos, sofreram muitas mudanças, mas as mudanças da linha não evoluíram na questão embalagens (ENTREVISTADO - TÉCNICO DE PCP).

O técnico de PCP também abordou a importância de discutir esse assunto dentro da empresa: "[...] precisamos urgente tomar decisões que determinem que tipos de embalagens que vamos usar para cada produto." Segundo ele, deveriam ser definidos parâmetros de embalagens para cada produto fabricado, levando em consideração o local de armazenamento e a sua utilização: "[...] este processo deve ser todo revisto, e determinar embalagens que acompanhe os itens no processo produtivo até o abastecimento sem a necessidade de manuseio durante os processos."
O técnico de logística, por sua vez, enfatizou o desenvolvimento dos novos produtos: "hoje temos todo um cuidado no desenvolvimento de novos produtos, com uma pessoa da logística, participando diretamente do processo de criação de embalagens, o que não acontecia tempo atrás." No que concerne ao melhoramento das embalagens, o almoxarife 2 acredita que existe a necessidade de uma "[...] negociação com fornecedores, para uma padronização das embalagens, $[\ldots]$ para que venha em uma embalagem que atenda à linha de montagem." Tal aspecto é relevante, uma vez que, no sistema da cadeia de suprimentos, as embalagens são capazes de exercer um impacto direto nos resultados de desempenho (ZAILANI et al., 2012).

\subsection{ANÁLISE DAS MOVIMENTAÇÕES}

Com o objetivo de reduzir os desperdícios em movimentações que não agregam valor ao produto, a décima quarta questão do roteiro de entrevista visou conhecer o que já existia e o que poderia ser melhorado no que concerne às movimentações. $\mathrm{O}$ coordenador da logística falou que hoje não existe um projeto específico dentro da logística: "[...] não tem uma equipe que faça a avaliação desse excesso de movimentação, e este excesso de movimentação está dentro das sete perdas logísticas; então nós não temos ainda implementado."

A esse respeito, o técnico da linha de montagem afirmou que, "[...] para reduzir a movimentação de pessoas e empilhadeiras, seria necessário agrupar o máximo de peças possível próximo à área de trabalho, $[. .$.$] as peças têm que$ estar próximas ao montador." Além disso, mencionou um agravante para a movimentação e o armazenamento na borda de linha, pois o fato de a linha de montagem ser uma linha multiproduto afeta bastante as movimentações dentro da linha devido à grande variedade de peças: "[...] como nós temos uma linha só, para todos os modelos desde o 4100, que é o menor, até o 7215, que é o maior de $215 \mathrm{cv}$, isso acarreta uma quantidade muito grande de itens dentro da linha."

$\mathrm{O}$ técnico de PCP, quando questionado 
sobre o tema, citou algumas mudanças que serão realizadas nos processos, como melhorias para redução de movimentações dentro da empresa. Segundo ele,

tem um projeto em andamento de colocar nas empilhadeiras um display, onde os pontos de coletas vão ter um botão, onde a pessoa, quando largar uma determinada carga para ser coletada, vai apertar este botão, e o display que está anexado na empilhadeira vai dizer para o motorista que naquele ponto ele tem uma determinada carga para coletar (ENTREVISTADO - TÉCNICO DE PCP).

\subsection{ANÁLISE DE SUGESTÕES DE MELHORIAS NA LOGÍSTICA}

A décima quinta questão do roteiro de entrevista destinava-se a saber se os entrevistados eram incentivados a apresentar sugestões de melhorias e o grau de implementação dessas sugestões dentro da logística. O técnico do PCP da empresa não trabalhava, diretamente, na logística, mas acreditava que existiam sugestões de melhorias, pois " $[. .$.$] a logística, nos últimos anos, vem$ evoluindo bastante na questão de melhorias, feitas dentro do seu próprio setor, tanto em questão de layout, organização, sistemas de armazenamento. São perceptíveis diversas melhorias as quais foram feitas dentro do processo logístico."

Quadro 2 - Sugestões de melhorias

\section{Função}

Técnico de logística

Almoxarife especializado

Almoxarife 2

Almoxarife 3

"Buscar valorizar as pessoas, para que se sintam valorizadas para que realizem e deem ideia para sempre estar melhorando com treinamentos e valorização".

"Na área do CKD, está meio defasado, não está estruturado, falta computadores para o pessoal trabalhar; o CKD é a área com mais dificuldade da logística hoje".

"Mostrar para cada colaborador deste setor e das outras áreas como funciona todos os procedimentos da logística, a movimentação de materiais, as movimentações no sistema, como é feito a entrada e a baixa dos materiais".

“Com treinamentos, maior diálogo, uma participação maior da gestão com os funcionários [...] maior utilização dos sistemas WMS e ABT que estão aí para nos ajudar e facilitar nosso trabalho".

Almoxarife 4

Técnico da linha de montagem

\section{"Treinamentos para melhorar o desempenho do pessoal".}

"Ter um acompanhamento mais de perto nesta área de abastecimento; na logística, deveria ser feito um estudo para avaliar os parâmetros dos itens com a disponibilidade do que estava disponível, o plano de montagem semanal".

Fonte: elaborado pelos autores (2018). 
Todas as contribuições trazidas pelos entrevistados buscam melhorar o desempenho da logística - entre essas sugestões, está o combate aos desperdícios. Isso evidencia a necessidade de melhorias nos treinamentos e de informações mais confiáveis, a fim de aprimorar a logística interna na empresa (BUONAMICO; MULLER; CAMARGO, 2017).

\subsection{ANÁLISE DAS INFORMAÇÕES E DOS TREINAMENTOS NA LO- GÍSTICA}

Nesta seção, são abordadas as principais informações necessárias para desempenhar um bom trabalho dentro da logística e quais os treinamentos fundamentais para esse tipo de trabalho. Assim, a décima sexta questão do roteiro de entrevista destinou-se a perguntar aos entrevistados quais informações julgavam necessárias para desempenhar um bom trabalho - esse aspecto ficou definido como uma subcategoria a posteriori na pesquisa.

Para o coordenador de logística, as principais informações são "o planejamento de produção, planejamento de compras e entregas [...], uma visão do que tem produzido e o que tem a receber para que as pessoas que são o miolo do processo consigam se organizar para fazer um bom dimensionamento na parte do recebimento e de abastecimento." Já o almoxarife 1 afirmou "nossa principal limitação é informações relacionadas a sistema; eu acredito que nós deveríamos ter mais informações e acessos aos sistemas utilizados, para conseguirmos realizar um trabalho mais eficiente." O inventarista, por sua vez, disse: "[...] como funciona sistema, como o WMS e ABT, nesta questão nos pecamos na logística."

Já o almoxarife 4 salientou que "todas as informações que estão diretamente relacionadas à área de logística" são muito importantes. E o almoxarife 3 mencionou ser necessária "uma boa integração sobre o nosso processo manual de orientação, [...] conseguir explicar sua função, porque dela está fazendo parte e a importância, explicar as informações necessá- rias se os funcionários tivessem um maior conhecimento do programa WMS."

Evidencia-se, assim, que faltam informações básicas para alguns entrevistados, principalmente no que concerne aos sistemas utilizados pela empresa. Trata-se de um ponto a ser bastante trabalhado para melhorar a área da logística organizacional.

A décima sétima questão do roteiro de entrevista visou conhecer a percepção dos entrevistados sobre os treinamentos necessários para a logística. Conforme o coordenador de logística,

ver os principais pontos que são gargalos, não só em nível de logística, mas em nível de empresa, e que a logística, muitas vezes, ela consegue fazer com que esses gargalos sejam eliminados por meio de uma logística diferente ou de uma interação diferente com a fábrica ou qualquer outra área (ENTREVISTADO - COORDENADOR DE LOGÍSTICA).

Para o técnico da linha de montagem, precisa-se de "treinamentos de sistemas de logística mesmo, como o Kanban, como funciona um Kanban, tempos de transportes, tempos de espera e itens que precisam passar por inspeção da qualidade."

E a vigésima questão, última do roteiro de entrevista, buscou saber se os participantes acreditam que o processo da logística pode ser executado de uma forma melhor que a atual. A seguir, no quadro 3, apresenta-se um resumo das respostas dadas pelos entrevistados. 
Quadro 3 - Opiniões sobre o processo logístico

Funções

\begin{tabular}{|c|c|c|}
\hline $\begin{array}{c}\text { Coordenador de } \\
\text { logística }\end{array}$ & $\begin{array}{c}\text { Ações } \\
\text { "Hoje tem muitas ferramentas, muitos softwares, onde tem muitos conceitos que } \\
\text { auxiliando o fornecedor, olhando toda a cadeia, ajudando a ter um processo muito } \\
\text { mais limpo, muito mais direto, que visa a reduzir o custo logístico". }\end{array}$ \\
\hline $\begin{array}{r}\text { Técnico de PCP } \\
\text { "Integrar melhor os sistemas e não trabalhar somente com a confiança no ser hu- } \\
\text { mano [...] integrar o conhecimento logístico com o conhecimento de montagem e } \\
\text { com o conhecimento de manufatura, [...] existe um potencial muito grande dentro de } \\
\text { todos os processos de montagem e produção". }\end{array}$ \\
\hline $\begin{array}{r}\text { Técnico de } \\
\text { logística }\end{array}$ & $\begin{array}{r}\text { "O processo de logística já foi bom, melhorou bastante e tem muito que melhorar". } \\
\hline \text { Almoxarife } 3\end{array}$ & $\begin{array}{r}\text { "No recebimento, na forma como as peças chegam, nas questões dos estrados, das embala- } \\
\text { gens, de como o WMS funciona, facilitaria a entrada das peças e a nossa movimentação". }\end{array}$ \\
\hline $\begin{array}{c}\text { Técnico da linha } \\
\text { de montagem }\end{array}$ & $\begin{array}{r}\text { "Todo o processo pode ser melhorado e deve ser melhorado, a melhoria contínua } \\
\text { como o caminho a seguir". }\end{array}$ \\
\hline Inventarista & "O caminho da melhoria contínua, hoje fizemos um processo que talvez daqui a um \\
ano não atenda nossas necessidades".
\end{tabular}

Fonte: elaborado pelos autores (2018).

Para Bardin (2004, p. 111), a "categorização é uma operação de classificação de elementos constituídos de um conjunto, por diferenciação e, seguidamente por reagrupamento segundo o gênero (analogia) com critérios previamente definidos." Nesta pesquisa, foram definidas a priori as seguintes categorias: metas e objetivos da pesquisa, gerenciamento de estoques, mentalidade enxuta, produção puxada e movimentações. No decorrer das entrevistas, definiram-se a posteriori mais algumas categorias: embalagens, pontos críticos e gargalos, informações e treinamentos e melhorias.

\subsection{ANÁLISE COM AUXÍLIO DE SOFTWARE}

Nesta seção, apresenta-se a análise das entrevistas realizadas. Os dados obtidos foram importados para o software NVIVO $11 \AA$, sendo posteriormente codificados e extraídos para análise. Esse processou possibilitou a execução de duas análises: uma realizada a partir dos nós, e outra efetuada com base nas fontes das pesquisas (entrevistas).

A partir da estrutura de nós criada, procedeu-se, também, à codificação teórica de Flick (2009), sendo utilizadas as três etapas por ele propostas: aberta, axial e seletiva. Por meio da estrutura de nós do software, foram obtidas as categorias e subcategorias que formam a codificação aberta e a codificação axial. Já a integração das subcategorias da codificação axial proporcionou a história do estudo de caso, que resultou na codificação seletiva.

$\mathrm{Na}$ codificação aberta, criaram-se as categorias, que depois foram codificadas (nós). Formaram-se, assim, categorias a priori, listadas com base no referencial teórico, buscando alcançar o objetivo proposto nesta pesquisa, e categorias a posteriori, elencadas com base nos dados obtidos de cada entrevistado, de acordo com as questões do roteiro das entrevistas.

Na codificação axial, foram identificadas as subcategorias dentro de cada nó da codificação aberta. Dentro de alguns nós, criaram-se subcategorias para auxiliar na análise e facilitar o alcance do objetivo proposto na pesquisa. Assim, foram fixadas categorias a priori, definidas com base em cada etapa do processo logístico da empresa: gerenciamento de estoques, metas e objetivos da logística, movimentações, análise dos processos, mentalidade enxuta e produção puxada. Além disso, foram definidas categorias a posteriori, estabelecidas no decorrer 
das entrevistas: embalagens, pontos críticos e gargalos, informações e treinamentos na logística.

$\mathrm{Na}$ codificação seletiva, foi desenvolvida a história do estudo de caso, permitindo a integração de todas as categorias e subcategorias. No quadro 4, exposto a seguir, consta a codificação teórica deste estudo.

Quadro 4 - Codificação teórica

\section{CODIFICAÇÃO TEÓRICA}

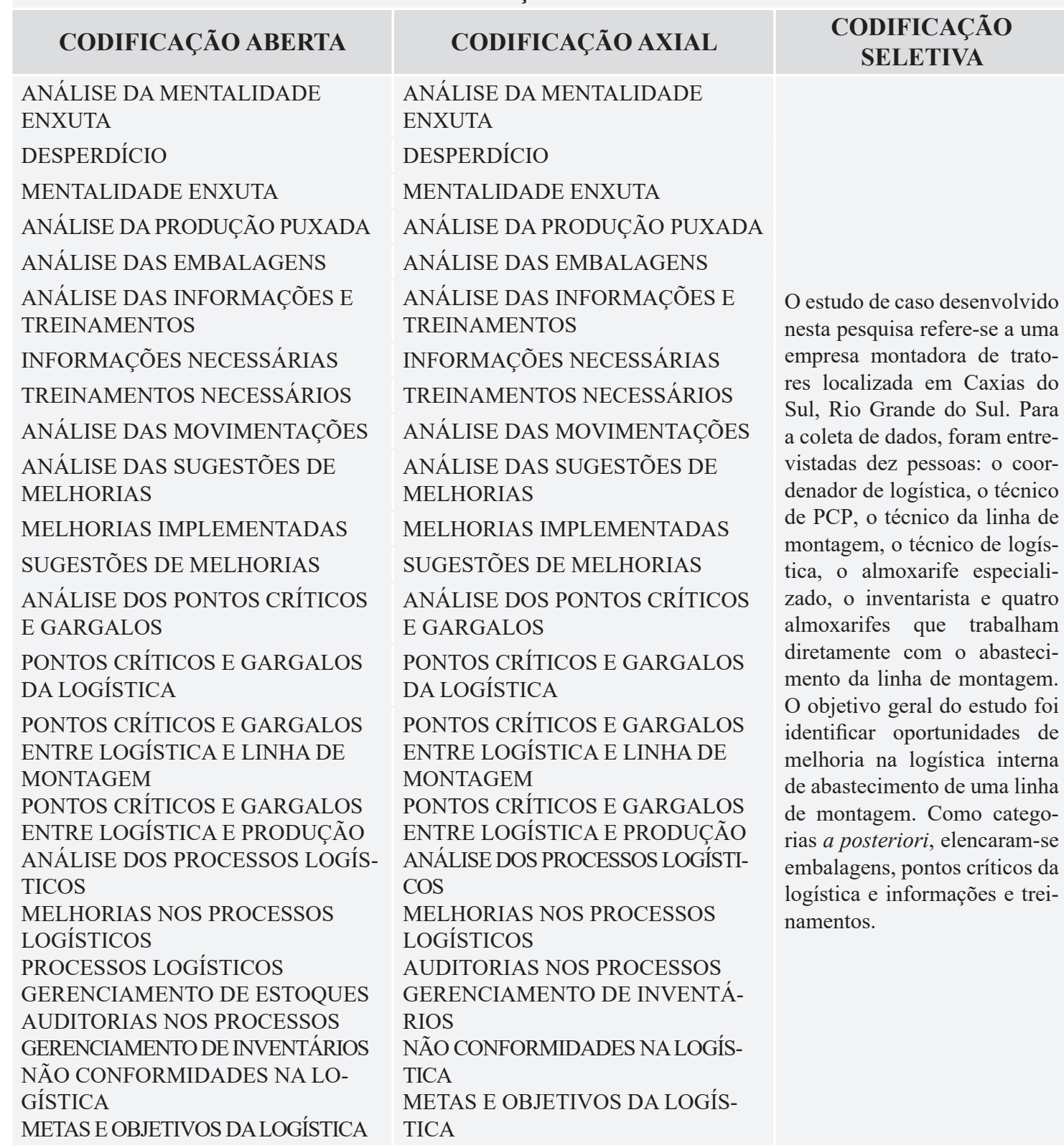

Fonte: elaborado pelos autores (2019).

\subsubsection{Análise dos nós}

As entrevistas realizadas com o coordenador da logística, o técnico de logística, o técnico de PCP, o técnico da linha de montagem, o almoxarife especializado, o inventarista e quatro almo- 
xarifes foram transcritas e importadas para o software NVIVO 11®, possibilitando a codificação em "nós". Essa estrutura de nós foi criada a partir das fontes (entrevistas) e referências (quantidade de vezes que foi codificado algum trecho da entrevista em determinado nó), como se pode observar no quadro 5.

Quadro 5 - Estrutura de nós no software NVIVO $11 \circledR$

NÓS

ANÁLISE DA MENTALIDADE ENXUTA

DESPERDÍCIO

MENTALIDADE ENXUTA

ANÁLISE DA PRODUÇÃO PUXADA

ANÁLISE DAS EMBALAGENS

ANÁLISE DAS INFORMAÇÕES E TREINAMENTOS

INFORMAÇÕES NECESSÁRIAS

TREINAMENTOS NECESSÁRIOS

ANÁLISE DAS MOVIMENTAÇÕES

ANÁLISE DAS SUGESTÕES DE MELHORIAS

MELHORIAS IMPLEMENTADAS

SUGESTÕES DE MELHORIAS

ANÁLISE DOS PONTOS CRÍTICOS E GARGALOS

PONTOS CRÍTICOS E GARGALOS DA LOGÍSTICA

PONTOS CRÍTICOS E GARGALOS ENTRE LOGÍSTICA E LINHA DE

MONTAGEM

PONTOS CRÍTICOS E GARGALOS ENTRE LOGÍSTICA E PRODUÇÃO

ANÁLISE DOS PROCESSOS LOGÍSTICOS

MELHORIAS NOS PROCESSOS LOGÍSTICOS

PROCESSOS LOGÍSTICOS

GERENCIAMENTO DE ESTOQUES

AUDITORIAS NOS PROCESSOS

GERENCIAMENTO DE INVENTÁRIOS

NÃO CONFORMIDADES NA LOGÍSTICA

METAS E OBJETIVOS DA LOGÍSTICA

Fonte: extraído do software NVIVO 11® (2019).

A partir da estruturação dos nós e da codificação das entrevistas, com as ferramentas do software NVIVO 11® foi possível estabelecer algumas relações entre as palavras. Nesse sentido, analisou-se, por exemplo, a frequência de palavras, que aponta a contagem de palavras relevantes na análise, possibilitando observar se os termos relacionados ao objetivo da pesquisa foram citados durante as entrevistas. Na nuvem de palavras, exposta a seguir, na figura 1, são demonstrados os termos mais relevantes da análise no que concerne à frequência em que esses termos foram usados.

\section{Fontes Referências}

0 0

$\begin{array}{ll}9 & 9\end{array}$

\begin{tabular}{l|l}
9 & 10
\end{tabular}

$10 \quad 12$

$10 \quad 22$

$\begin{array}{ll}0 & 0\end{array}$

$10 \quad 10$

$10 \quad 10$

10

$\begin{array}{ll}0 & 0\end{array}$

$10 \quad 12$

\begin{tabular}{l|l}
10 & 27
\end{tabular}

0

$10 \quad 10$

10

$10 \quad 11$

0

\begin{tabular}{l|l}
9 & 9
\end{tabular}

$10 \quad 10$

$\begin{array}{ll}0 & 0\end{array}$

$10 \quad 11$

$10 \quad 12$

$10 \quad 10$

$10 \quad 10$

(a)

2

(2)

(1)

0

10

0

27

0

10

10

11

0

9

10

0

11

12

10

10


Figura 1 - Nuvem de palavras dos "nós"

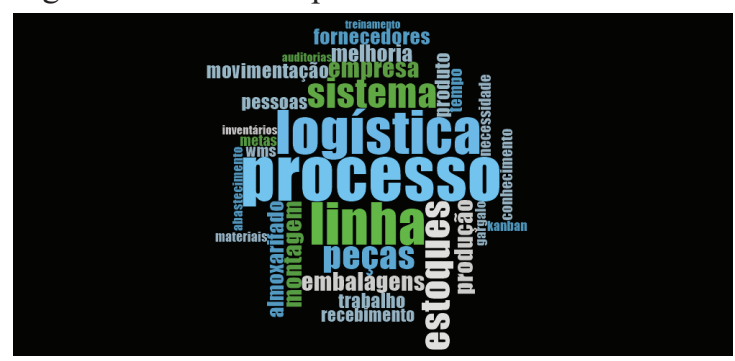

Fonte: extraído do software NVIVO 11 ( (2017).

O software indicou relações entre termos como "almoxarifado" (citado 40 vezes) e "movimentação" (citado 37 vezes), evidenciando o impacto que as movimentações de materiais ocasionam no almoxarifado. Para Castiglioni (2013), a movimentação de materiais pode ser definida como todo o deslocamento físico de materiais dentro de uma instalação.

Os "estoques" (citado 79 vezes) de "materiais" (citado 22 vezes) estão relacionados a "metas" (citado 25 vezes) e a "inventário" (citado 19 vezes), termos esses que mostram a relevância dos inventários de materiais para alcançar as metas de redução dos estoques dentro de uma empresa. Já "trabalho" (citado 35 vezes) está ligado a "tempo" (citado 30 vezes), evidenciando a relevância do tempo para o trabalho e o quanto o fato de estar no tempo certo e no ponto de uso impacta os materiais, afetando diretamente o trabalho efetuado em determinado processo.

Por fim, destaca-se, conforme prevê Moura (1999), que a "produção" (citado 46 vezes) da "empresa" (citado 48 vezes) pode utilizar o "Kanban" (citado 22 vezes) como uma das técnicas para puxar a produção.

\section{CONSIDERAÇÕES FINAIS}

Considerando que a proposta desta pesquisa consistiu em identificar oportunidades de melhoria na logística interna do abastecimento de uma linha de montagem multiproduto em uma empresa de tratores de Caxias do Sul, é possível afirmar que o objetivo em questão foi atendido. Constatou-se, inicialmente, uma falta de informações básicas para os profissionais que trabalham com o abastecimento das linhas, aspecto evidenciado, por exemplo, pelo fato de desconhecerem os planos de montagem da semana, a previsão de chegadas das peças e as peças que precisam ser produzidas com maior agilidade por estar em falta e serem necessárias para finalizar produtos posicionados no final da linha de montagem. Esses quesitos impactam diretamente a montagem, de forma que a logística da empresa precisa criar meios efetivos para disseminar as informações aos profissionais que trabalham diretamente no abastecimento.

Além disso, ficou evidente, nas entrevistas, que as embalagens utilizadas na empresa não atendem à logística e ao abastecimento na borda de linha, gerando retrabalho no recebimento, na armazenagem, no abastecimento das peças e na montagem dos produtos. As embalagens devem partir do fornecedor e passar por todos os processos da empresa até chegar à borda de linha, a fim de evitar movimentações, retrabalhos e danos nos materiais.

Embora a empresa tenha criado, recentemente, um manual de embalagem com todas as informações relacionadas às embalagens, esse manual não era conhecido pelos técnicos de PCP e da linha de montagem, que são o principal fornecedor e o principal cliente da logística interna da empresa. As embalagens constituem um ponto crítico dentro da empresa, que pode ser trabalhado para aumentar o desempenho da logística e diminuir os custos dos produtos, otimizando recursos e aumentando qualidade.

Ressalta-se, ainda, a falta de confiabilidade nos fluxos de informações entre as áreas de logística, PCP e linha de montagem, fator apontado pelos entrevistados. A deficiência nos fluxos de informações está atrelada aos sistemas usados pela empresa, uma vez que não há conexão entre esses sistemas no controle das informações. Também foi destacada a ineficiência do sistema WMS da logística, pois as informações não são confiáveis, e as pessoas que trabalham no operacional da logística não têm os acessos necessários para desempenhar suas funções, acarretando ineficiência do trabalho executado.

Diante disso, cabe mencionar que a gestão 
da logística tornou-se uma vantagem competitiva para as empresas por tratar de um processo estratégico na aquisição, na movimentação, na armazenagem e no abastecimento de materiais e no fluxo de informações, demonstrando a relevância da pesquisa desenvolvida. Neste estudo de caso, foram identificadas oportunidades de melhorias por meio das sugestões e opiniões dos funcionários entrevistados, possibilitando ações de acordo com as necessidades específicas do processo logístico interno da empresa Agrale S.A.

Conclui-se que a empresa não possui alinhamento operacional entre funcionários do mesmo setor, aspecto identificado pela falta de informações básicas para os profissionais que trabalham com o abastecimento das linhas. Dessa forma, mesmo que a empresa, além de comprar os insumos, planeje a mão de obra e a produção, os funcionários que executam as tarefas não recebem todas as informações necessárias para o desempenho de sua função, ocasionando perdas.

É preciso citar, ainda, algumas limitações desta pesquisa, com destaque ao fato de que o estudo de caso único não permite fazer generalizações quanto aos resultados apresentados. Em relação a pesquisas futuras, sugere-se uma análise sobre outra área da empresa, uma vez que esta pesquisa limitou-se a identificar oportunidades na área da logística com foco na ótica da própria logística. Assim, este estudo pode ser aplicado, por exemplo, sob a ótica dos setores de produção e linha de montagem, podendo, também, ser realizado a partir de uma abordagem quantitativa.

\section{REFERÊNCIAS}

AGRALE S.A. Perfil financeiro. Arquivo da empresa, 2014.

BARCELOS JÚNIOR, H. O papel da logística na cadeia produtiva: um estudo de caso. 2002 . 101 f. Dissertação (Mestrado em Engenharia de Produção) - Programa de Pós-Graduação em Engenharia de Produção, Universidade Federal de Santa Catarina, Florianópolis, 2002. Disponível em: https://repositorio.ufsc.br/xmlui/han- dle/123456789/83498. Acesso em: 4 set. 2016. BARDIN, L. Análise de conteúdo. 3. ed. Lisboa: Edições 70, 2004.

BOYSEN, N. et al. Part logistics in the automotive industry: decision problems, literature review and research agenda. European Journal of Operational Research, v. 242, p. 14, 2015.

BUONAMICO, N.; MULLER, L.; CAMARGO, M. A new fuzzy logic-based metric to measure lean warehousing performance. Supply Chain Forum: An International Journal. Taylor \& Francis, v. 18, n. 2, p. 96-111, 2017.

CASTIGLIONI, J. A. M. Logística operacional: guia prático. 3. ed. São Paulo: Érica, 2013. Disponível em: https://integrada.minhabiblioteca.com.br/\#/books/9788536505770/. Acesso em: 1 nov. 2016.

CHOPRA, S.; MEINDL, P. Gerenciamento da cadeia de suprimentos: estratégia, planejamento e operações. 6. ed. São Paulo: Pearson Education do Brasil, 2016.

DIEHL, A. A.; TATIM, D. C. Pesquisa em ciências sociais aplicadas: métodos e técnicas. São Paulo: Pearson, 2004.

DUBEY, R. et al. Sustainable supply chain management: framework and further research directions. Journal of Cleaner Production, v. 142, p. 1119-1130, 2017.

FENG, Y.; ZHU, Q.; LAI, K. H. Corporate social responsibility for supply chain management: A literature review and bibliometric analysis. Journal of cleaner production, v. 158, p. 296-307, 2017.

FIGUEIREDO, K. F.; FLEURY, P. F.; WANKE, P. F. (org.). Logística e gerenciamento da cadeia de suprimentos: planejamento do fluxo de produtos e dos recursos. São Paulo: Atlas, 2013. Disponível em: https://ucsvirtual.ucs.br/ startservico/MIB/. Acesso em: 24 abr. 2015. 
FLICK, U. Introdução à pesquisa qualitativa. Tradução Joice Elias Costa. 3. ed. Porto Alegre: Artmed, 2009.

GIL, A. C. Como elaborar projetos de pesquisa. 5. ed. São Paulo: Atlas, 2010. Disponível em: https://ucsvirtual.ucs.br/. Acesso em: 13 out. 2016.

GRANT, D. B. Gestão de logística e cadeia de suprimentos. São Paulo: Saraiva, 2013.

LAKATOS, E. M.; MARCONI, Marina de Andrade. Metodologia científica. 6. ed. São Paulo: Atlas, 2011. Disponível em: https://ucsvirtual.ucs.br/startservico/MIB/. Acesso em: 15 out. 2016.

LIN, J. et al. The extension and exploitation of the inventory and order based production control system archetype from 1982 to 2015 . International Journal of Production Economics, v. 194, p. 135-152, 2017.

MOREIRA, D. A. Administração da produção e operações. São Paulo: Saraiva, 2012. Disponível em: http://integrada.minhabiblioteca.com.br/\#/ books/9788502180420/cfi/148!/4/4@0.00:4.33. Acesso em: 16 jan. 2017.

MOURA, R. A. Kanban: a simplicidade do controle da produção. 5.ed. São Paulo: IMAM Editora e Comércio LTDA, 1999.

NOGUEIRA,A. S. Logística empresarial: uma visão local com pensamento globalizado. São Paulo: Atlas, 2012. Disponível em: https://integrada.minhabiblioteca com.br/\#/books/9788522477708/. Acesso em: 24 out. 2016.

PAOLESCHI, B. Cadeia de Suprimentos. São Paulo: Érica, 2014. Disponível em: https://integrada.minhabiblioteca.com.br/\#/ books/9788536513324/. Acesso em: 15 set. 2016.

PIPLANI, R.; ANG, A. W. H. Performance comparison of multiple product kanban control systems. International Journal of Production Research, v. 56, n. 3, p. 1299-1312, 2018.

PIRES, S. R. I. Gestão da cadeia de suprimentos (Supply Chain Management): conceitos, estratégias, práticas e casos. 2. ed. São Paulo: Atlas, 2009.

RODRIGUES, M. G. Abastecimento de materiais numa linha de montagem final multiproduto. 2016. 74 f. Dissertação (Mestrado) - Curso de Faculdade de Engenharia de Guaratinguetá, Universidade Estadual Paulista, Guaratinguetá, 2016.

SIMECS. Sindicato das Indústrias Metalúrgicas, Mecânicas e de Material Elétrico de Caxias do Sul. Perfil socioeconômico. 2017. Disponível em: www.simecs.com.br. Acesso em: 15 mar. 2017.

TEIXEIRA, E. C. Mapeamento da logística interna em uma empresa do setor de autopeças. 2008. 107 f. Dissertação (Mestrado) - Curso de Curso de Mestrado em Administração, Universidade Federal de Lavras, Lavras, 2008.

WANG, H.; GONG, Q.; WANG, S. Information processing structures and decision making delays in MRP and JIT. International Journal of Production Economics, v. 188, p. 41-49, 2017.

YAZDANI, M. et al. A group decision making support system in logistics and supply chain management. Expert Systems with Applications, v. 88, p. 376-392, 2017.

ZAILANI, S. et al. Sustainable supply chain management (SSCM) in Malaysia: A survey. International Journal of Production Economics, v. 140, n. 1, p. 330-340, 2012.

Agradecimentos: "O presente trabalho foi realizado com o apoio da Coordenação de Aperfeiçoamento de Pessoal de Nível Superior - Brasil (CAPES) - Código de Financiamento 001", conforme PORTARIA No 206, DE 4 DE SETEMBRO DE 2018". 